\title{
A potential scavenger of carbon radicals for ancient carbonized silk fabrics: Superoxide Dismutase (SOD)
}

\author{
Xiaojian Bai, Yuxuan Gong, Haiyan Yang and Decai Gong*
}

\begin{abstract}
Superoxide Dismutase (SOD) was proposed as a potential scavenger of carbon radicals in ancient carbonized silk fabrics. Ancient and artificially carbonized silk samples were treated using this method. The optimal experimental conditions of the treatment were determined by variance analysis. The effects of the scavenging on carbonized silks were investigated by electron paramagnetic resonance (EPR). The results showed that the carbon radicals in both ancient and artificially carbonized silks were cleared to a great extent. The ageing resistance of the treated samples and scanning electron microscope (SEM) images of samples before and after treatment ensured that the treatment would not aggravate the deterioration of silk. Thus, the potential of SOD to scavenge carbon radicals in historic silk was demonstrated. Our research may help to alleviate further degradation which could occur during preservation of silk.
\end{abstract}

Keywords: Ancient carbonized silk, Carbon radicals, Scavenger, Superoxide dismutase

\section{Introduction}

The production of silk fabric was a great invention in the history of human civilization. Numerous archaeological excavations have proved that sericulture emerged in the Yellow River Basin and the Yangtze River Basin as early as 5000 years B.P. In approximately the third century B.C., silk began to be transported to other countries through the Silk Road, which promoted cultural and economic communications. As silk is susceptible to different ambient factors, e.g. light, heat, water, and microorganisms, most of the historic silk fabrics lost their mechanical strength and became brittle, research on the mechanism of silk degradation is still at a groping stage [1,2]. In a previous article [3], we studied several ancient silk fabrics by means of electron paramagnetic resonance (EPR) and Raman spectrometry, and discovered carbon radicals accumulated in them. The Raman spectra showed two peaks (D and G), which are indicative of carbonization. The EPR spectra of the ancient samples showed a characteristic sharp absorption centered at $\mathrm{g}=2.0037$ without a hyperfine structure, and have been identified as those of carbon

\footnotetext{
* Correspondence: gdclucky@ustc.edu.cn

Department of History of Science and Scientific Archaeology, Basic Research Center of Conservation Science, University of Science and Technology of China, Hefei 230026, Anhui, P.R. China
}

radicals. Thus, this kind of ancient silk fabrics was referred to as carbonized silk. Although these carbon radicals were relatively stable during burial after thousands of years, more carbon radicals will generate after excavation as the environment changed totally and cause further degradation in ancient silk fabrics [4-6]. Therefore, it is necessary to scavenge the fresh carbon radicals in carbonized silk in order to avoid potential hazards.

Superoxide dismutase (SOD) is an important oxidoreductase against oxidation damage $[7,8]$. It is soluble in water and can be used under room-temperature. Due to the $100 \%$ protein composition which is similar to silk protein, SOD is highly compatible with silk. The mild experimental conditions could ensure other forms of preservation will not be affected $[9,10]$. Thus, SOD solution can be a candidate scavenger for carbon radicals within ancient silk fabrics.

The present study aimed to demonstrate the capability of SOD as a potential radical scavenger for ancient silk fabrics. Because genuine historic silk fabrics were not appropriate for a large number of repeated tests, artificially carbonized silk samples were used as substitutes. To determine the optimal experimental conditions, variance analysis of double factors cross classification without repetition was performed. The scavenging effects were characterized by EPR. 
The ageing resistance of the scavenged samples was evaluated via dynamic mechanical analysis (DMA). Then, the method was applied to ancient carbonized silk fabrics. The fibre morphology of samples before and after treatment were observed using scanning electron microscope (SEM).

\section{Experimental}

\section{Materials}

Ancient carbonized samples were unearthed from Balingshan Tomb (403 B.C.-221 B.C.), in Jingzhou, Hubei Province, China, denoted as JZ (Figure 1). Modern silks were supplied by Guanghua Silk Co. Ltd. Superoxide dismutase (BR, activity $1750 \mathrm{U} / \mathrm{mg}$ ) was manufactured by Worthington Ltd.

\section{Preparation of artificially carbonized samples}

According to references $[11,12]$, modern silks were heated under $230^{\circ} \mathrm{C}$ for $40 \mathrm{~h}$ to obtain artificially carbonized samples with exceedingly low strength, denoted as 40hTH. JZ was heated under $230^{\circ} \mathrm{C}$ for $6 \mathrm{~h}(6 \mathrm{hJZ})$ to mimic the generation of fresh carbon radicals in storage.

\section{Determination of experimental conditions}

The SOD solutions with concentrations of $0.01 \%, 0.05 \%$, $0.10 \%, 0.20 \%(\mathrm{w} / \mathrm{v})$ were prepared by dissolving SOD into distilled water. The scavenger solutions were sprayed onto $40 \mathrm{hTH}$ (the sample area to mixture volume ratio was $1 \mathrm{~cm}^{2}: 10 \mu \mathrm{L}$ ) at room-temperature for $24 \mathrm{~h}$ and $48 \mathrm{~h}$ respectively. Variance analysis of double factors cross classification without repetition was performed to obtain the optimal concentration and scavenging time.

\section{Evaluation methodology for the scavenging effects}

The scavenging effects were evaluated by analysis of samples before and after scavenging with electron paramagnetic resonance. For EPR measurements, each sample was weighed and placed into standard quartz EPR tubes.

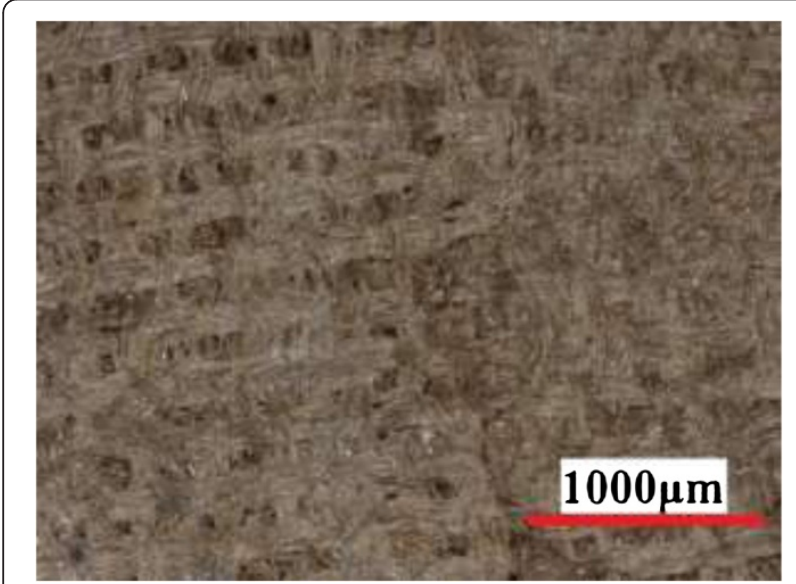

Figure 1 Micrographs $(\times 100)$ of JZ (scale bar, $1000 \mu \mathrm{m})$.
The EPR spectra were performed with a JEOL JESFA200 EPR spectrometer at room temperature. The microwave frequency was $9.06 \mathrm{GHz}$, the microwave power was $0.998 \mathrm{~mW}$, and the modulation amplitude was $0.35 \mathrm{mT}$. All signal intensities were normalized to be equated with sample weighed $1 \mathrm{mg}$.

The clearance rate of carbon radicals through the change of EPR signal intensity was calculated as follows.

The clearance rate of carbon radicals on 40hTH:

$$
m_{1}=\frac{I_{0}-I^{\prime}}{I_{0}}
$$

where $I_{o}$ and $I^{\prime}$ represent the EPR signal intensity of the sample before and after applying scavenger respectively, $m_{1}$ is the clearance rate of carbon radicals.

The clearance rate of newly generated carbon radicals on 6hJZ:

$$
m_{2}=\frac{\left(I-I_{0}\right)-\left(I^{\prime}-I_{0}\right)}{I-I_{0}}=\frac{I-I^{\prime}}{I-I_{0}}
$$

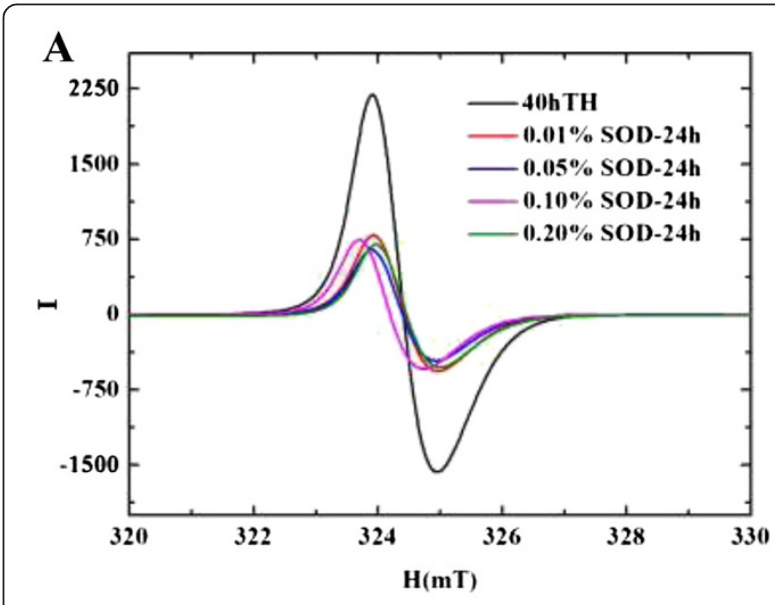

B

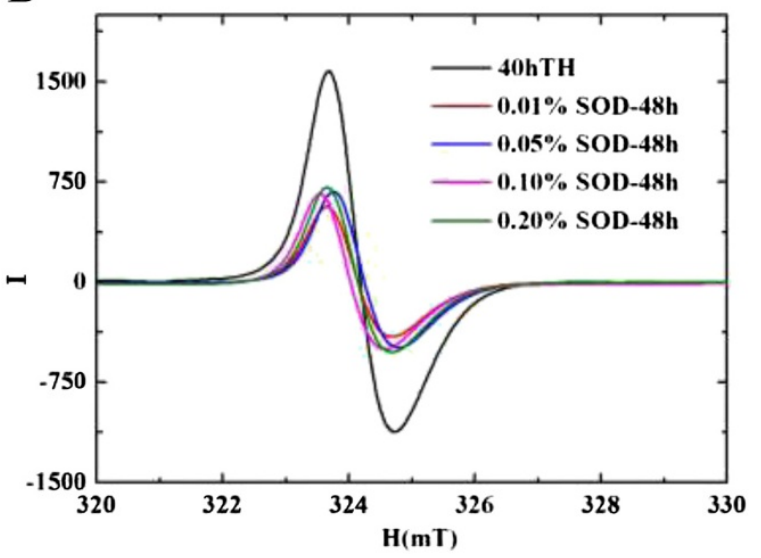

Figure 2 The EPR results of 40hTH before and applied with SOD solution with different concentrations (A) time of treatment $=24 \mathrm{~h}$ (B) time of treatment $=48 \mathrm{~h}$. 
Table 1 Clearance rates (\%) on $40 \mathrm{hTH}$ by applying SOD

\begin{tabular}{llllll}
\hline $\begin{array}{l}\text { Scavenging } \\
\text { time A (h) }\end{array}$ & \multicolumn{6}{l}{ Mass fraction of SOD solution B (\%) } \\
\cline { 2 - 6 } & $\mathbf{0 . 0 1}$ & $\mathbf{0 . 0 5}$ & $\mathbf{0 . 1 0}$ & $\mathbf{0 . 2 0}$ & $\mathbf{x}_{\mathbf{i}}$ \\
\hline 24 & 64.0 & 71.1 & 65.8 & 67.6 & 67.1 \\
48 & 64.3 & 57.2 & 57.4 & 54.3 & 58.3 \\
$\mathrm{x}_{\mathrm{j}}$ & 64.2 & 64.2 & 61.6 & 61.0 & \\
\hline
\end{tabular}

where $I_{0}$ represents the EPR signal intensity of the ancient fabric before artificial carbonization. $I$ represents the EPR signal intensity of the ancient fabric after artificial carbonization. $I^{\prime}$ represents the EPR signal intensity of the ancient fabric which was artificially carbonized and applied with SOD.

\section{Aging resistance assessment}

40hTH before and after being treated with $0.05 \%$ SOD solution was artificially aged at $60^{\circ} \mathrm{C}$ and relative humidity of $80 \%$ for $72 \mathrm{~h}$ and cut into strips of $1.0 \mathrm{~cm} \times$ $5.0 \mathrm{~cm}$. Then the tensile strength of these samples was examined using using a Dynamic Mechanical Thermal Analyzer Q800 (TA instruments Inc., USA). Five replicates were analyzed for each sample.

\section{Fibre morphology observation}

SEM images of the ancient carbonized silk fabrics fibres and artificially carbonized silk samples before and after treatment by the superoxide Dismutase (SOD) were observed with a JEOL JSM-6700 F scanning electron microscope at $5.0 \mathrm{keV}$ accelerating voltage. Samples were mounted on an aluminum stub and sputtered with aurum before observed.

\section{Results and discussions}

40hTH were treated with SOD solution at different concentrations and time spans. The EPR spectra of $40 \mathrm{hTH}$ applied with SOD solution at various experimental conditions were shown in Figure 2. The EPR spectra of the samples showed a characteristic sharp absorption centered at $\mathrm{g}=2.0037$ without a hyperfine structure, and have been identified as those of carbon radicals [3]. It is clear that a multitude of carbon radicals were generated in the artificially carbonized silk samples. And after treatment by SOD with various experimental conditions, the amount of

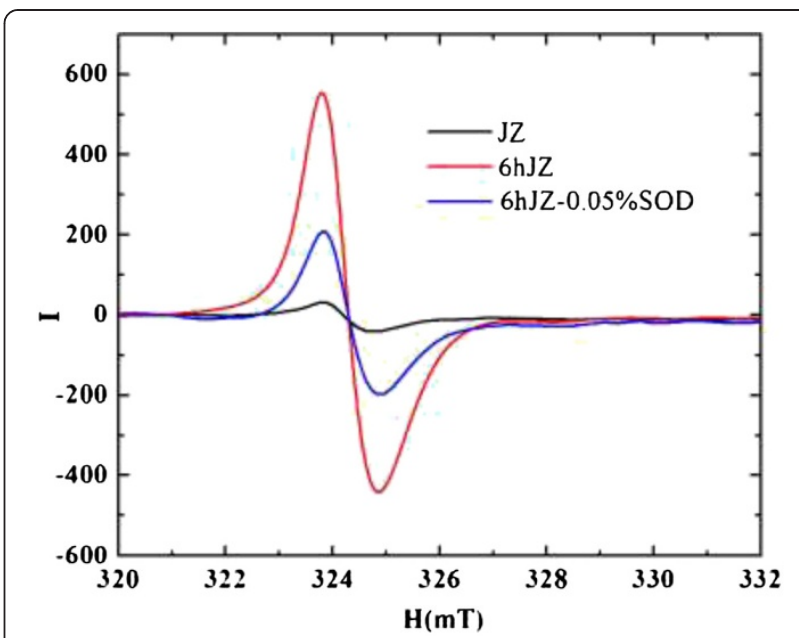

Figure 3 EPR results of $\mathrm{JZ}$ which is artificially carbonized for $6 \mathrm{~h}$ and applied with SOD for $24 \mathrm{~h}$.

carbon radicals declined to a large extent. On the basis of EPR results, the clearance rates of carbon radicals were calculated (Table 1). Afterwards, variance analysis of double factors cross classification without repetition was adopted based on all data calculated (Table 2), whereby the optimal experimental conditions were selected.

Table 1 shows the clearance rates after treatment by SOD on $40 \mathrm{hTH}$ are between $61 \%$ and $71 \%$, and the choice of $0.05 \%$ SOD and scavenging time of $24 \mathrm{~h}$ would achieve the best results. The variance analysis results in Table 2 indicated that Factor A and Factor B are insignificant for clearance rate. It means that with the increment of the mass fraction from $0.01 \%$ to $0.20 \%$ and scavenging time from $24 \mathrm{~h}$ to $48 \mathrm{~h}$, there is no obvious variation between the results. That means SOD can achieve good scavenging effect under low concentration and little time. Therefore, concentration of $0.05 \%$ SOD and scavenging time of $24 \mathrm{~h}$ were adopted as optimal experimental conditions.

In this experiment: $a=2, b=4$

Primary hypothesis: $\mathrm{H}_{0 \mathrm{~A}}: \alpha_{1}=\alpha_{2}=\cdots \cdots=\alpha_{a}=0$

$$
\mathrm{H}_{0 \mathrm{~B}}: \beta_{1}=\beta_{2}=\cdots \cdots=\beta_{b}=0
$$

Total mean value $\bar{x}_{. .}=62.7$

Table 2 Results of variance analysis

\begin{tabular}{|c|c|c|c|c|c|c|}
\hline Causes of deviation & $\begin{array}{l}\text { Variation sum } \\
\text { of squares }\end{array}$ & $\begin{array}{l}\text { Degree of } \\
\text { freedom }\end{array}$ & $\begin{array}{l}\text { Variances of } \\
\text { measurement }(\mathrm{V})\end{array}$ & F-value & $\begin{array}{l}\text { The critical } \\
\text { value of F-test }\end{array}$ & Significance \\
\hline Factorial effect of $A$ & 154.88 & 1 & 154.88 & 7.19 & 10.13 & $\overline{\text { insignificance }}$ \\
\hline Factorial effect of B & 17.2 & 3 & 5.73 & 0.27 & 9.28 & insignificance \\
\hline Error effect & 64.63 & 3 & 21.54 & & & \\
\hline Total & 237.33 & 7 & & & & \\
\hline
\end{tabular}


Table 3 The DMA results of hygrothermal aging $40 \mathrm{hTH}$ which were treated by different scavengers

\begin{tabular}{ll}
\hline Sample & Tensile strength (MPa) \\
\hline 40hTH after hygrothermal aging & 3.296 \\
$\begin{array}{l}\text { 40hTH treated by SOD after } \\
\text { hygrothermal aging }\end{array}$ & 3.883 \\
\hline
\end{tabular}

$$
\begin{aligned}
& Q_{A}=b \sum_{i=1}^{4}\left(\bar{x}_{i}-\bar{x}_{. .}\right)^{2}=154.88 \\
& Q_{B}=a \sum_{j=1}^{4}\left(\bar{x}_{j}-\bar{x}_{. .}\right)^{2}=17.2 \\
& Q_{E}=\sum_{i=1}^{2} \sum_{j=1}^{4}\left(x_{i j}-\bar{x}_{i}-\bar{x}_{j}+\bar{x}_{. .}\right)^{2}=64.63 \\
& Q_{T}=\sum_{i=1}^{2} \sum_{j=1}^{4}\left(x_{i j}-\bar{x}_{. .}\right)^{2}=237.33 \\
& V_{A}=\frac{Q_{A}}{a-1} . V_{B}=\frac{Q_{B}}{b-1} \\
& V_{E}=\frac{Q_{E}}{(a-1)(b-1)} \\
& F_{A}=\frac{V_{A}}{V_{E}}=7.19 \\
& F_{(0.05,1,3)}=10.13 \\
& F_{B}=\frac{V_{B}}{V_{E}}=0.27
\end{aligned}
$$

$$
F_{(0.05,3,3)}=9.28
$$

$\mathrm{F}_{\mathrm{A}}<\mathrm{F}_{(0.05,1,3)}$, thus primary hypothesis $\mathrm{H}_{0 \mathrm{~A}}$ is conformed, $\mathrm{F}_{\mathrm{B}}<\mathrm{F}_{(0.05,3,3)}$, primary hypothesis $\mathrm{H}_{0 \mathrm{~B}}$ is also conformed.

As shown in Figure 3, a large amount of fresh free radicals were generated after accelerated carbonization, indicating the potential threat of ancient silk during storage. After SOD solution was applied, the calculation shows $\mathrm{m}_{2}$ is $65.6 \%$, suggesting that SOD solution can effectively scavenge the fresh free radicals generated after excavation.

Ensuring that the treatment would not exacerbate degradation is vital to a novel conservation method. Although SOD has not been used on silk before, there are related studies proving that SOD will not have longterm effects on other protein-based materials, such as skin and food [13-15]. Tensile strength of artificially carbonized and scavenged samples after hygrothermal ageing are compared in Table 3. Obviously, there is no impact on the tensile strength of the samples from application with SOD solution. As shown in Figure 4, after treatment by the superoxide Dismutase (SOD), the fiber morphology of both the ancient carbonized silk fabrics fibres and artificially carbonized silk samples are almost the same as that before treatment. Hence, the treatment would not precipitate the ageing process of silk fabrics.

\section{Conclusions}

The newly-discovered carbon radicals in silk can be an adverse factor related to the preservation of silk artifacts. Superoxide Dismutase (SOD) was used to scavenge carbon radicals in ancient and artificially carbonized silk fabrics. The experimental conditions of this treatment

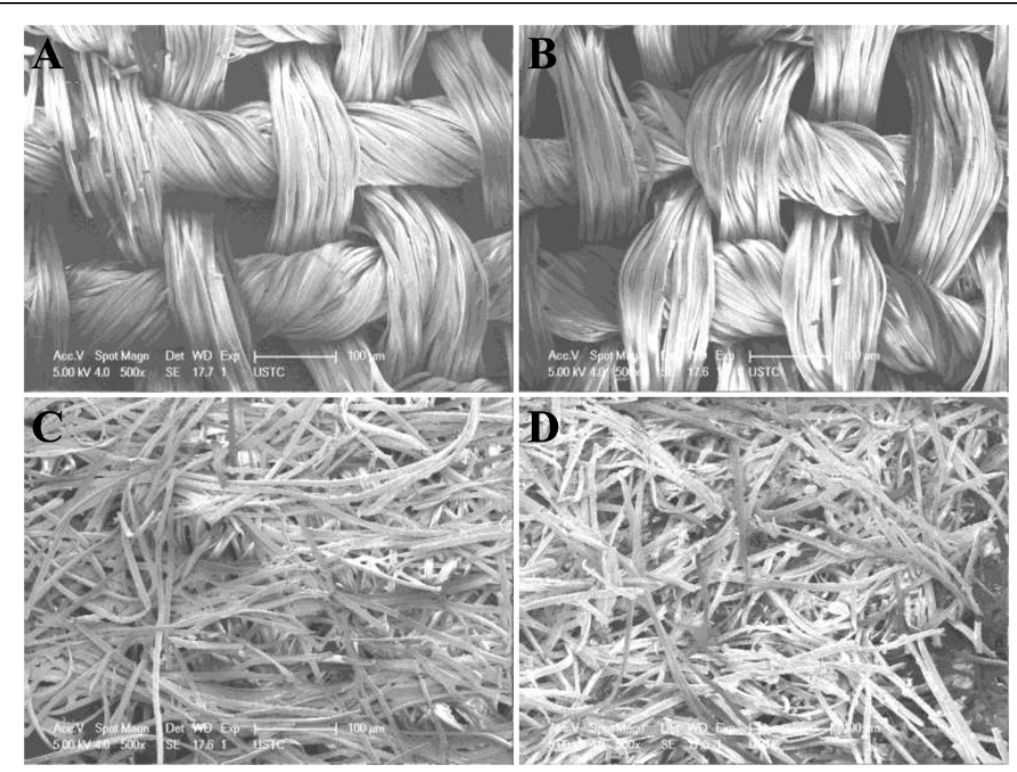

Figure 4 SEM images $(\times 500)$ of silk samples before and after SOD treatment (A) 40hTH before treatment (B) $40 \mathrm{hTH}$ after treatment (C) $6 \mathrm{hJZ}$ before treatment (D) $6 \mathrm{hJZ}$ after treatment. 
were determined through variance analysis. It was found that the fresh carbon radicals generated during storage can be effectively scavenged through this method. In addition, the ageing effects of the treated samples and SEM images of samples before and after treatment suggest that this treatment would not accelerate the ageing of silk fabrics. Therefore, the candidacy of SOD as a candidate scavenger of carbon radicals for ancient carbonized silk was demonstrated preliminarily.

Competing interests

The authors declared that they have no competing interests.

\section{Authors' contributions}

XB designed the experiment; prepared the samples; performed the data analysis; wrote the manuscript. YG helped for writing and revised the article. HY performed analyses and interpreted results of EPR. DG helped for designing the experiment; revised the article. All authors read and approved the final manuscript.

\section{Acknowledgements}

This work was financially supported by the Key Projects in the National Science \& Technology Pillar Program of China during the 11 th Five-Year Plan period (2010BAK67B13). The EPR and DMA experiments were performed at Instruments' Center for Physical Science, University of Science and Technology of China. Technical support from Dr. Zhanyun Zhu was gratefully acknowledged.

Received: 10 April 2014 Accepted: 5 November 2014

Published online: 22 November 2014

\section{References}

1. Zhu Z, Gong D, Liu L, Wang Y: Microstructure elucidation of historic silk (Bombyx mori) by nuclear magnetic resonance. Anal Bioanal Chem 2014 doi:10.1007/s00216-014-7660-8.

2. Zhu Z, Chen H, Li L, Gong D, Gao X, Yang J, Zhao X, Ji K: Biomass spectrometry identification of the fibre material in the pall imprint excavated from grave M1, Peng-state Cemetery, Shanxi, China. Archaeometry 2013, n/a-n/a, doi:10.1111/arcm.12029.

3. Gong $\mathrm{D}$, Yang $\mathrm{H}$ : The discovery of free radicals in ancient silk textiles. Polym Degrad Stabil 2013, 98:1780-1783. doi:10.1016/j. polymdegradstab.2013.05.011

4. Rowe LJ, Maddock KR, Lonergan SM, Huff-Lonergan E: Influence of early postmortem protein oxidation on beef quality. J Anim Sci 2004, 82:785-793.

5. Renerre M, Poncet K, Mercier Y, Gatellier P, Métro B: Influence of dietary fat and vitamin $\mathrm{E}$ on antioxidant status of muscles of turkey. J Agr Food Chem 1999, 47:237-244.

6. Trouillas $P$, Bergès J, Houée-Lévin C: Toward understanding the protein oxidation processes: $\mathrm{OH}$ addition on tyrosine, phenylalanine, or methionine? Int J Quantum Chem 2011, 111:1143-1151.

7. Liochev SI, Fridovich I: Mechanism of the peroxidase activity of $\mathrm{Cu}, \mathrm{Zn}$ superoxide dismutase. Free Radical Bio Med 2010, 48:1565-1569.

8. Hodgson EK, Fridovich I: Interaction of bovine erythrocyte superoxide dismutase with hydrogen peroxide: inactivation of the enzyme. Biochemistry 1975, 14:5294-5299.

9. Wang S, Shao B, Liu S, Ye X, Rao P: Purification and characterization of Cu, Zn-superoxide dismutase from black soybean. Food Res Int 2012, 47:374-379.

10. Searcy $\mathrm{D}: \mathrm{HS}^{-}: \mathrm{O}_{2}$ oxidoreductase activity of $\mathrm{Cu}, \mathrm{Zn}$ superoxide dismutase. Arch Biochem Biophys 1996, 334:50-58.

11. Zhu Z, Gong D: Determination of the experimental conditions of the transglutaminase-mediated restoration of thermal aged silk by orthogonal experiment. J Cult Herit 2014, 15:18-25. doi:10.1016/j. culher.2012.12.002

12. Zhu Z, Liu L, Gong D: Transglutaminase-mediated restoration of historic silk and its ageing resistance. Herit Sci 2013, doi:10.1186/2050-7445-1-13.
13. Claira D, Zhao $Y$, Chaiswing I, Oberley T: Modulation of skin tumorigenesis by SOD. Biomed Pharmacother 2005, 59:209-214.

14. Quéré S, Lacan D, Lemaire B, Carillon J, Schmitt K: The role of superoxide dismutase (SOD) in skin disorders. Nutrafoods 2014, 13:13-27.

15. Meyer A, Rorbak K, Adler-Nissen J: Critical assessment of the applicability of superoxide dismutase as an antioxidant in lipid foods. Food Chem 1994, 51:171-175

doi:10.1186/s40494-014-0027-9

Cite this article as: Bai et al: A potential scavenger of carbon radicals for ancient carbonized silk fabrics: Superoxide Dismutase (SOD). Heritage Science 2014 2:27.

\section{Publish with ChemistryCentral and every scientist can read your work free of charge \\ "Open access provides opportunities to our colleagues in other parts of the globe, by allowing anyone to view the content free of charge." W. Jeffery Hurst, The Hershey Company.}

- available free of charge to the entire scientific community

- peer reviewed and published immediately upon acceptance

- cited in PubMed and archived on PubMed Central

- yours - you keep the copyright

Submit your manuscript here

http://www.chemistrycentral.com/manuscript/<smiles>c1ccccc1</smiles>

Chemistry Central 